\title{
ALIH KODE DAN CAMPUR KODE PADA PERCAKAPAN KESEHARIAN DI LINGKUNGAN FAKULTAS SYARIAH DAN EKONOMI ISLAM
}

\author{
Syukriati \\ FEBI UIN Mataram \\ dewi.abidjar@gmail.com
}

\begin{abstract}
This study aims to examine the problems of form, type, purpose and factors that cause the process of code switching and code mixing in the daily conversations of lecturers and staff at the Faculty of Sharia and Islamic Economics. This type of research is qualitative descriptive research. Data collection in this study uses skillful listening techniques while data analysis uses extralingual equivalent methods. The research location was at the Faculty of Sharia and Islamic Economics IAIN Mataram. While the object of research is daily conversation at the Faculty of Sharia and Islamic Economics IAIN Mataram. The results of the findings of this study are the form of code switching and code mixing found in the form of words, phrases and clauses. The type of code transfer that is found is internal code switching (inner code-switch) and the type of code mixing found in the form of mixing code into (inner mixing-code). While the purpose of code switching is found in the form of: affirmation, debilitating, certainty, curiosity, explanation, quips, suggestions, offers and notifications. The purpose of the code mix was found in the form of: respect, affirmation, ambiguity, wonder, specific, anger, culture, information, curiosity, prohibition and appeal. Factors that cause code switching are: opposed to speaking and the presence of third speakers. While the causes of interfering code are: desire factors to explain, variety identification factors and role identification factors.
\end{abstract}

Keywords: code mixing, code switching, sociolinguistics, speech events

\footnotetext{
Abstrak: Penelitian ini bertujuan untuk menngkaji persoalan wujud, jenis, tujuan dan faktoryang menyebabkan terjadi proses alih kode dan campur kode dalam percakapan keseharian dosen dan staf di Fakultas Syariah dan Ekonomi Islam. Jenis penelitian ini yaitu penelitian deskriptif kualitatif.Pengumpulan data dalam penelitian ini menggunakan teknik simak libat cakap sedangkan analisis data menggunakan metode padan ekstralingual.Lokasi penelitian di Fakultas Syariah dan Ekonomi Islam IAIN Mataram.Sedangkan objek penelitiannya yaitu percakapan keseharian di Fakultas Syariah dan Ekonomi Islam IAIN Mataram. Adapun hasil dari temuan penelitian ini yaitu wujud alih kode dan campur kode yang ditemukan yaitu berwujud kata, frasa dan klausa.Jenis alih kode yang ditemukan adalah alih kode internal (inner code-
} 
switch) dan jenis campur kode yang ditemukan berupa campur kode ke dalam (inner mixing-code). Sedangkan tujuan alih kode yang ditemukan berupa: penegasan, melemahkan, kepastian, penasaran, penjelsan, menyindir, saran, tawaran dan pemberitahuan. Adapun tujuan campur kode yang ditemukan berupa: penghormatan, penegasan, ambiguitas, keheranan, spesifik, marah, budaya, informasi, penasaran, larangan dan himbauan. Faktor penyebab alih kode berupa: lawan tutur dan hadirnya penutur ketiga. Sedangkan faktor penyebab campur kode berupa: faktor keinginan untuk menjelaskan, faktor identifikasi ragam dan faktor identifikasi peranan.

Kata Kunci: alih kode, campur kode, sosiolinguistik, peristiwa tutur

\section{A. Pendahuluan}

Pada masyarakat Indonesia yang terdiri dari bermacam-macam budaya, ras dan etnik dengan sendirinya terdapat pula berbagai macam variasi bahasa yang digunakan untuk berkomunikasi antar anggota masyarakatnya.Berkaitan dengan hak ini, masyarakat Indonesia merupakan masyarakat multibahasa yang sarat dengan permasalahan bahasa.Pemakaian bahasa dalam masyarakat yang dwibahasa atau multibahasa merupakan gejala yang menarik untuk dikaji.

Peristiwa yang lazim terjadi pada pemakaian bahasa oleh masyarakat yang dwibahasa atau multibahasa yaitu peristiwa yang sering disebut dengan alih kode dan campur kode. Alih kode (code switching) adalah peristiwa peralihan dari satu kode ke kodeyang lain ${ }^{1}$ Misalnya penutur menggunakan bahasa Indonesia beralih menggunakan bahasa Jawa. Alih kode merupakan salah satu aspek ketergantungan bahasa (language dependency) dalam masyarakat multilingual ${ }^{2}$. Dalam masyarakat multilingual sangat sulit seorang penutur mutlak hanya menggunakan satu bahasa. Sedangkan campur kode (code-mixing) terjadi apabila seorang penutur menggunakan suatu bahasa secara dominan mendukung suatu tuturan disisipi dengan unsur bahasalainnya. Hal ini biasanya berhubungan dengan karakteristk penutur, seperti latar belakang sosial, tingkat pendidikan, rasa keagamaan. Biasanya ciri menonjolnya berupa kesantaian atau situasi informal. Namun bisa terjadi karena keterbatasan bahasa, ungkapan dalam bahasa tersebut tidak ada padanannya, sehingga ada keterpaksaan menggunakan bahasa lain, walaupun hanya mendukung satu fungsi. Campur kode termasuk juga konvergense kebahasaan (linguistic convergence). ${ }^{3}$

Jenis penelitian ini adalah penelitian deskriptif kualitatif dengan metode padan dengan teknik simak karena akan mendeskripsikan bagaimana wujud, jenis, tujuan

1 Abdul Chaer dan Leonie Agustina. Sosiolinguistik Perkenalan Awal. Jakarta: Rineka Cipta. 2004, h.107.

2 Ridan Umi Darojah, "Pengertian Alih Kode dan Campur Kode", dalam http://ridanumidarojah. blogspot.co.id/2013/05/pengertian-alih-kode-dan-campur-kode.html, diambil tanggal 3 April 2017, pukul 10.54 WITA

3 Komunitas Anak Sastra, "Sosiolinguistik: Alih Kode dan Campur Kode", dalam http://anaksastra. blogspot.co.id/2009/02/alih-kode-dan-campur-kode.html, diambil tanggal 3 April 2017 pukul 11.13 WITA 
dan faktor yang menyebabkan terjadinya alih kode dan campur kode bahasa Sasak dan bahasa Indonesia yag terjadi dalam percakapan sehari-hari.

Fenomena peralihan bahasa ini juga terjadi di lingkungan kampus IAIN Mataram, yang juga merupakan tempat tugas dari peneliti, dimana para karyawan dan dosen disana tidak hanya berasal dari Mataram dan Lombok akan tetapi juga berasal dari berbagai daerah lainnya di wilayah NTB seperti Dompu, Bima, Sumbawa dan bahkan berasal dari luar NTB seperti Jawa, Sumatera dan Sulawesi. Para civitas akademik yang mayoritas berasal dari Lombok tentunya menggunakan bahasa asli Lombok untuk berkomunikasi sehari-hari yaitu bahasa Sasak, sementara peneliti sendiri berasal dari Bima yang mana tidak menggunakan bahasa Sasak sebagai bahasa percakapan sehari-hari di lingkungan kampus.

\section{B. Landasan Teori}

Alih kode adalah peristiwa peralihan kode yang satu ke kode yang lain, jadi apabila seorang penutur mula-mula menggunakan kode A (misalnya bahasa Sasak), dan kemudian beralih menggunakan kode B (misalnya bahasa Sumbawa), maka peristiwa peralihan pemakaian bahasa seperti itu disebut alih kode (code-switching) (Suwito, 1983: 68). Adapun menurut Ohoiwutun (1997: 71) alih kode (code switching), yakni peralihan pemakaian dari satu bahasa atau dialek ke bahasa atau dialek lainnya. Dengan demikian, alih kode itu merupakan gejala peralihan pemakaian bahasa yang terjadi karena situasi dan terjadi antarbahasa serta antarragam dalam satu bahasa (Aslinda dan Leni, 2007: 85).

Menurut Myres dan Scotton alih kode adalah peralihan penggunaan kode satu ke kode bahasa yang lainnya. Apabila seseorang mula-mula menggunakan kode bahasa A, misalnya bahasa Sasak, kemudian beralih menggunakan bahasa B misalnya bahasa Indonesia, peralihan pemakaian seperti itu disebut alih kode (code-swtching). Menurut (Kitu 2014: 52) alih kode merupakan salah satu aspek tentang saling ketergantungan bahasa (language depedency) di dalam masyarakat multilingual hampir tidak mungkin seorang penutur menggunakan bahasa secara murni tanpa sedikit pun memanfaatkan bahasa atau unsur bahasa yang lain. Dari uraian alih kode yang relatif senada, dapat disimpulkan bahwa alih kode adalah proses peralihan bahasa yang satu ke bahasa yang lain yang disebabkan oleh hal-hal tertentu sesuai dengan situasi yang ada.

Campur kode adalah suatu keadaan berbahasa lain bilamana orang mencampur dua (atau lebih) bahasa atau ragam dalam suatu tindak bahasa (speech act atau discourse) tanpa ada sesuatu dalam situasi berbahasa itu yang menuntut percampuran bahasa itu (Nababan, 1984: 32). Menurut Thelander (Suwito, 1983: 76) apabila suatu tuturan terjadi percampuran atau kombinasi antara variasi-variasi yang berbeda di dalam suatu klausa yang sama, maka peristiwa tersebut disebut campur kode.

Menurut Rokhman (Ulfiani, 2014: 97) campur kode adalah pemakaian dua bahasa atau lebih dengan saling memasukkan unsur bahasa yang satu ke dalam bahasa 
yang lain untuk memperluas gaya bahasa. Menurut Kridalaksana (Susmita, 2015:98) campur kode adalah penggunaan satuan bahasa dari satu bahasa ke bahasa yang lain untuk memperluas gaya bahasa atau ragam bahasa. Dari beberapa pendapat di atas dapat disimpulkan bahwa campur kode adalah penggunaan dua bahasa atau lebih yang berupa serpihan (pieces) untuk memperluas ragam bahasa atau gaya bahasa dalam suatu percakapan.

\section{Metode Penelitian}

Pendekatan yang digunakan dalam penelitian ini adalah pendekatan deskriptif kualitatif karena penelitian ini bertujuan untuk memberikan gambaran atau deskripsi tentang suatu keadaan secara objektif.Pendekatan deskriptif kualitatif dapat digunakan untuk menggambarkan peristiwa kebahasaan secara objektif baik bahasa lisan maupun tulisan. ${ }^{4}$ Dalam artikel ini, peristiwa kebahasaan yang dikaji adalah peristiwa alih kode dan campur kode dalam percakapan dosen di lingkungan Fakultas Syariah dan Ekonomi Islam IAIN Mataram.Pengumpulan data dalam penelitian ini dilakukan dengan teknik simak sedangkan analisis data dilakukan dengan menggunakan metode agih dengan teknik urai unsur terkecil yaitu mengurai suatu satuan lingual tertentu atas unsur-unsur terkecilnya.Metode agih adalah metode analisis data dengan alat penentunya justru bagian dari bahasa yang bersangkutan itu sendiri (Sudaryanto dalam Akmaluddin, 2016)..$^{5}$

\section{Pembahasan}

\section{Alih Kode}

Wujud alih kode yang ditemukan dalam penelitian ini berupa kata sejumlah 5 , bentuk frasa 8, dan bentuk klausa sejumlah 16 data.

Adapun jenis alih kode yang ditemukan adalah alih kode ke dalam (inner code switch). Alih kode ke dalam berupa peralihan bahasa Indonesia ke bahasa Sasak, atau sebaliknya peralihan dari bahasa Sasak ke bahasa Indonesia. Peralihan yang terjadi berdasarkan pada situasi dan pokok pembicaraan.Memang tidak bisa dinafikan bahwa kebiasaan seseorang secara sepontanitas melakukan peralihan bahasa tutur jika ada interest dan kesesuaian dengan keadaan yang dianggap tepat oleh penutur dan mitra tutur.

Sementara itu tujuan alih kode yang ditemukan dalam penelitian ini yaitu: a). penegasan, b). melemahkan, c).kepastian, d). penasaran, e).penjelasan, f).menyindir, g). saran, h). tawaran dan i).pemberitahuan.

4 Akmaluddin, Jurnal Mabasan Vol. 12 No. 1 Tahun 2018 "Realitas Penggunaan bahasa Indonesia Ragam Tulisan pada Lembaga Penmerintahan” (Mataram: Kantor Bahasa Provinsi NTB, 2018), hlm. 7.

5 Jurnal Mabasan Vol. 10 No. 2 Tahun 2016 "Problematika Bahasa Indonesia Kekinian: Sebuah Analisis KesalahanBerbahasaIndonesia Ragam Tulisan" (Mataram: Kantor Bahasa Provinsi NTB, 2018), hlm. 7. 
a). Penegasan

\begin{tabular}{|l|l|l|}
\hline Bpk 4 & $:$ & gak ada di sini rei \\
\hline Ibu 5 & $:$ & yang nganterin itu kan pernah kita ketemu di fak tarbiyah \\
\hline Bpk 4 & $:$ & endekn te taoqn? \\
\hline Ibu 5 & $:$ & Endeqn \\
\hline \multicolumn{2}{l}{ Kode data: $(A K / W K /$ Rek 03/42:34/2017) } \\
\hline
\end{tabular}

Kata 'endeqn' merupakan penegasan bahwa penutur Ibu 5 memang benar-benar tidak tau sosok yang dimaksudkan oleh penutur Bpk 4. Kata 'endeqn' dikeluarkan oleh penutur Ibu 5 sebagai penegasan agar penutur Bpk 5 tidak mempertanyakan itu lagi sebab sejatinya penutur Ibu 4 tidak mengenal dan tidak tau siapa sosok yang dimaksud oleh penutur Bpk 5 tersebut.

\begin{tabular}{|l|c|l|}
\hline Bpk 1 & $:$ & Ape unin teparan program tye baruq? \\
\hline Bpk 3 & $:$ & Saq embe? \\
\hline Bpk 1 & $:$ & Saq baruq \\
\hline Bpk 3 & $:$ & Program scan sudah itu! \\
\hline Bpk 1 & $:$ & Oke mantap \\
\hline \multicolumn{2}{|l}{ Kode data: $($ AK/WF/Rek 02/10:15/2017) } \\
\hline
\end{tabular}

Frasa 'saq embe' merupakan penegasan bahwa penutur Bpk 3 memang tidak tau dengan pasti nama program yang dimaksud oleh penutur Bpk 1. Frasa 'saq embe' dikeluarkan oleh penutur Bpk 3 sebagai penegasan agar penutur Bpk 1 tidak mempertanyakan sesuatu yang tidak diketahui oleh penutur Bpk 3, sebab sejatinya penutur Bpk 3 tidak mengetahui dengan pasti nama program yang dimaksud oleh penutur Bpk 1. Karena dipaksa maka penutur Bpk 3 menjawab apa adanya yang jauh dari kebenaran nama program yang dimaksdkan oleh pneutur Bpk 1.

b). melemahkan

\begin{tabular}{|l|c|l|}
\hline Ibu 1 & $:$ & Besok masuk kan? \\
\hline Ibu 2 & $:$ & Ohh...pasti delima...hehe \\
\hline Ibu 2 & $:$ & Daahh... \\
\hline Ibu 1 & $:$ & Tu kan, pasti besok datengnya kesiangan \\
\hline Ibu 1 & $:$ & Oya, Jurnal muamalahnya mana? \\
\hline Bpk 1 & $:$ & Saq ne? \\
\hline Ibu 1 & $:$ & Enggaqn? \\
\hline Bpk 1 & $:$ & Enggaqn araq sekeq \\
\hline Kode data: (AK/WK/Rek 02/14:40/2017) \\
\hline
\end{tabular}


Kata 'enggaqn' yang dilontarkna oleh penutur Ibu 1 merupakan tuturan yang melemahkan mitra tutur Bpk 1.Kata tersebut dilontarkan seperti nada mengolok penutur Bpk 1. Kata tersebut juga merupakan pengalihan kode bahasa dari bahasa Indonesia sebagai bahasa pertama yang digunakan dalam tuturan tersebut kemudian berubah menjadi tuturan komunikasi dalam bahasa Sasak disebabkan oleh materi tutur.Kata 'enggaqn' juga diutarakan sebagai manifestasi konkrit dari ketidakcukupan koleksi jurnal muamalah yang dilihat oleh penutur Ibu 1 tersebut. Oleh karena tuturan penutur Ibu 1 melalui alihkode kata tersebut menjadi pelemahan terhadap lawan tutur.

c). Kepastian

\begin{tabular}{|l|c|l|}
\hline Bpk 1 & $:$ & Niniq? \\
\hline Bpk 2 & $:$ & Ndeq niniq ne! \\
\hline Bpk 1 & $:$ & Brembe tan model nani ne? \\
\hline Bpk 1 & $:$ & Kirim ke sini! \\
\hline Bpk 2 & $:$ & Oh iya \\
\hline \multicolumn{2}{|l|}{ Kode data: (AK/WK/Rek 02/ 24:37/2017) } \\
\hline
\end{tabular}

Kata 'niniq' merupakan kata permintaan kepastian yang diutarakan oleh penutur Bpk 1 kepada lawan tutur Bpk 2. Kata tersebut diujarkan karena menjadi bagian dari ketidakjelasan pola dan proses input data sejak diberlakukan system baru. Kata 'niniq' juga memiliki kedekatan tujuan dengan rasa ingin tahu akan kejelasan proses input data mahasiswa. Disamping itu juga kata tersebut diujarkan sebagai sbuah antisipasi jika saja proses situ benar-benar berubah dalam input data Mata Kuliah, maka penutur Bpk 1 bisa melakukan tindakan lain yang bisa mempermudah proses input data MK itu sendiri.

\begin{tabular}{|l|c|l|}
\hline Ibu 3 & $:$ & Naa kan tadi ngajar yang mana yang mana? Yang ini kan! \\
\hline Ibu 2 & $:$ & Atas sedikit \\
\hline Ibu 2 & $:$ & Cobaq cobaq \\
\hline Ibu 3 & $:$ & IKITI oneq no? \\
\hline Ibu 2 & $:$ & Iya bu \\
\hline Ibu 4 & $:$ & SK mengajar genap! kita lihat dulu ini yang di atas \\
\hline Ibu 2 & $:$ & Mengajar muamalah \\
\hline Kode data: (AK/WF/ Rek 02/26:23/2017) \\
\hline
\end{tabular}

Frasa 'cobaq-cobaq' merupakan bentuk kepastian yang ingin diperoleh oleh penutur Ibu 2 terhadap tuturan dari penutur Ibu 3.Frasa tersebut diujarkan karena penutur Ibu 2 ingin memastikan bahwa apakah mata kuliah yang diajarkan sudah sesuai dengan jadwal yang tertera ataukah tidak. Tindakan tersebut dilakukan karena 
beberapa dosen mengalami prubahan ampuan jadwal mata kuliah.Oleh sebab itu penutur Ibu 2 memastikan bahwa MK yang diampu sudah sesuai.

Sementara itu, frasa 'oneq no' merupakan balasan kepastian yang diberikan oleh penutur Ibu 3 terhadap permintaan kepastian dari penutur Ibu 2. Frasa tersebut diujarkan karena penutur Ibu 3 merasa bahwa apa yang dilihat oleh penutur Ibu 2 seolah-olah benar padahal itu bukanlah MK dia. Hal tersebut dilakukan oleh penutur Ibu 3 sebagai bentuk sikap meyakinkan penutur Ibu 2 agar tidak khwatir dengan jadwal MK yang diampu.

d). Penasaran

\begin{tabular}{|l|c|l|}
\hline Ibu 3 & $:$ & oh araq kabel datam atau ndeq pengecas? \\
\hline Bpk 2 & $:$ & Aneeh, ndeq jauq! \\
\hline Bpk 2 & $:$ & OTG jaq araq ni! \\
\hline Ibu 3 & $:$ & Ape aran OTG? \\
\hline Bpk 2 & $:$ & Flashdisk leq hp tye! \\
\hline Ibu 3 & $:$ & Embe? \\
\hline Bpk 2 & $:$ & Oh ne ne \\
\hline Bpk 2 & $:$ & Kirim file Pdf atau kirim ke Email? \\
\hline Ibu 3 & $:$ & Pdf saja! \\
\hline Kode data: (AK/WK/ Rek 02/16:319/2017) \\
\hline
\end{tabular}

Kata 'embe' merupakan bentuk rasa penasaran yang diujarkan oleh penutur Ibu 3.Hal itu dilakukan karena ketidaktahuan yang dimiliki oelh penutur Ibu 3 tentang jenis kabel OTG.Ketidaktahuan penutur Ibu 3 dengan istilah yang diujarkan oleh penutur Bpk 2 kemudian menjadi rasa ingin tau yang cukup besar bagi penutur Ibu 3.

\begin{tabular}{|l|c|l|}
\hline Bpk 1 & $:$ & Ape unin teparan program tye baruq? \\
\hline Bpk 3 & $:$ & Saq embe? \\
\hline Bpk 1 & $:$ & Saq baruq \\
\hline Bpk 3 & $:$ & Program scan sudah itu! \\
\hline Bpk 1 & $:$ & Oke mantap \\
\hline Kode data: (AK/WKel/Rek 02/10:15/2017) \\
\hline
\end{tabular}

Klausa 'ape unin teparan program tiye baruq' merupakan bentuk rasa penasaran yang diujarkan oleh penutur Bpk 1 terhadap satu jenis program yang sedang digunakan oleh temannya. Tindakan ini dilakukan karena program tersebut dalah program baru dan semua dosen sudah menggunakannya sementara penutur Bpk 1 belum memilikinya. Rasa penasaran atau ingin tahunya tentang program itu cukup besar karena akan menunjang produktifitasnya dalam menyelesaikan urusan akademik. 
e). Penjelasan

\begin{tabular}{|l|c|l|}
\hline Ibu 3 & $:$ & Minuman ini kadaluarsa semua? \\
\hline Bpk 2 & $:$ & Iye unin. \\
\hline Ibu 3 & $:$ & Segerah ne. pacuan \\
\hline Bpk 2 & $:$ & Segerah ke gelutm \\
\hline Ibu 4 & $:$ & Awas mbk El..hati-hati \\
\hline Ibu 3 & $:$ & Beneran ya mbk ini kadalwarsa? \\
\hline Ibu 4 & $:$ & Kayaknya sih mbk \\
\hline Bpk 2 & $:$ & Minum aja kalau Ibu mau \\
\hline Bpk 2 & $:$ & Hahaha... \\
\hline Kode data: (AK/WF/ Rek 02/13:00/2017) \\
\hline
\end{tabular}

Frasa 'iye unin' merupakan kata penjelas dari ujaran penutur Bpk 2 terhadap lawan tutur Ibu 3.Tuturan tersebut keluar sebagai penjelas dari pertanyaan penutur Ibu 3.Tindakan tersebut dilakukan untuk memberikan gambaran minuman yang sedang ditanyakan oleh penutur Ibu 3.Hal tersebut juga untuk menghindari hal-hal yang tidak diinginkan terjadi pada penutur Ibu 3 seperti keracunan.

\begin{tabular}{|l|l|l|}
\hline Bpk 4 & $:$ & Ndarak kesimpen model-odel pengiriman ne leq te? \\
\hline Bpk 3 & $:$ & Pengiriman model ATK nu \\
\hline Bpk 4 & $:$ & ye wah \\
\hline Bpk 3 & $:$ & oh, ndaraq mun sak nu jak. Wah bih siq tulakang doang \\
\hline Bpk 4 & $:$ & Saya piker ente simpan bro \\
\hline Bpk 3 & $:$ & Kalau gak penting ngapain disimpan pak \\
\hline \multicolumn{2}{|l}{ Kode data: (AK/WF/ Rek 03/49:43/2017) } \\
\hline
\end{tabular}

Frasa 'ye wah' merupakan bentuk penjelas yang tidak membutuhkan pertanyaan lagi.Tuturan tersebut dicapkan oleh penutur Bpk 4 sebagai wujud informasi lanjutan atas jawaban dari penutur Bpk 3 yang mempertanyakan pengiriman alat tulis ATK. Frasa tersebut dikategorikan penjelas karna mampu meminimalkan munculnya pertanyaan kembali.

\begin{tabular}{|l|l|l|}
\hline Ibu 4 & $:$ & Yakm kembe? \\
\hline Bpk 2 & $:$ & Kerisaq date bapak no ne \\
\hline Ibu 4 & $:$ & Ape jaq tie \\
\hline Bpk 2 & $:$ & Ndeq taoq no anuq bapakn? \\
\hline Ibu 4 & $:$ & Loh, bukannya ini presensi Surfiks 2G Paredasrik \\
\hline Bpk 2 & $:$ & Iya, presensi 2G Surfiks PS \\
\hline \multicolumn{2}{|l}{ Kode data: (AK/WKel/ Rek 02/12:20/2017) } \\
\hline
\end{tabular}


Klausa 'kerisaq date bapak no ne?' merupakan penjelas terhadap pertanyaan dari penutur Ibu 4 tentang aktifitas yang sedang dilakukan oleh penutur Bpk 2. Tuturan yang berupa klausa tersebut diutarakan penutur Bpk 2 guna memberikan keterangan aktifitas yang sedang dilakukan agar tidak menimbulkan kesan yang tidak-tidak.

f). Menyindir

aissslah, mulain sugul sombongn

\begin{tabular}{|l|l|l|}
\hline Ibu 3 & $:$ & Hadiah apa beli ini ? \\
\hline Bpk 3 & $:$ & Beli. \\
\hline Ibu 3 & $:$ & Berapa? \\
\hline Bpk 3 & $:$ & Dewi yang beli \\
\hline Ibu 3 & $:$ & Dapet seratus ribu? \\
\hline Bpk 3 & $:$ & Bayar dah buk \\
\hline Ibu 3 & $:$ & Kok murah sekali ? \\
\hline Bpk 3 & & Aissslah, mulain sugul sombongn. \\
\hline Ibu 3 & & Endeq ape menu...hahaha \\
\hline Kode data: (AK/WKel/ Rek 01/14:21/2017) \\
\hline
\end{tabular}

Klausa 'aissslah mulain sugul sombongn' merupakan bentuk sindiran yang diujarkan oleh penutur Bpk 3 terhadap sikap tutur dari penutur Ibu 3. Ujaran sindiran dalam bentuk klausa tersebut sebagai bentuk akumulasi sikap yang ditunjukkan oleh penutur Bpk 3 terhadap ujaran-ujaran yang bernada meninggikan diri yang dilakukan oleh penutur Ibu 3 seperti 'koq murah sekali' dan lain-lainnya.

g). Saran

cobaq saq lain mun suruq

\begin{tabular}{|l|l|l|}
\hline Bpk 3 & $:$ & embe lain pak syarif nu \\
\hline Bpk 4 & $:$ & ye lalo ngaji \\
\hline Bpk 3 & $:$ & ngaji apa, ngisi pengajian? \\
\hline Bpk 4 & $:$ & ngisi ngaji di matematika \\
\hline Bpk 3 & $:$ & isiq ngaji terus endeq tebayah bareh no \\
\hline Bpk 3 & $:$ & cobaq saq lainan mun suruq \\
\hline \multicolumn{2}{|l}{ Kode data: (AK/WKel/ Rek 03/14:32/2017) } \\
\hline
\end{tabular}

Klausa 'cobaq saq lain mun suruq' merupakan bentuk saran yang diujarkan oleh penutur Bpk 3 terhadap mitra tuturnya yaitu Bpk 4. Ujaran dalam bentuk klausa di atas sebagai bentuk tawaran agar dosen yang dimaksud memberikan kesempatan bagi dosen lain yang memiliki kompetensi dalam bidang dakwah. Ujaran tersebut 
juga sebagai bentuk peyakinan akan kompetensi dosen yang dimaksud oleh penutur Bpk 3.

h). Tawaran

Bpk 4 : wahm boye film PK nu pak?

Bpk 3 : apa jak film PK?

Bpk 4 : Amir khan nu

Bpk 4 : Film tentang pencarian kebenaran agama-agama itu

Bpk 3 : Bagus filmnya?

Bpk 4 : Solah gati nu pak

Bpk 3 : Maeh kopiang ite menu jaq

Kode data: (AK/WKel/Rek 03/16:34/2017)

Klausa ' wahm boye film PK nu?' merupakan bentuk tawaran yang diujarkan oleh penutur Bpk 4 terhadap lawan tuturnya yaitu Bpk 3. Pada data tersebut penutur Bpk 4 mencoba menawarkan sebuah film yang penutur Bpk 3 tidak tau bahkan belum menontonya sama sekali. Hal tersebut bisa dilihat dari respon yang diberikan oleh penutur Bpk 3 yang memunculkan pertanyaan tentang apa sih film PK tersebut. Ujaran dalam bentuk klausa tersebut sebagai klarifikasi yang dilakukan oleh penutur Bpk 4 terhadap update-an film dari penutur Bpk 3.

i). Pemberitahuan

\begin{tabular}{|l|l|l|}
\hline Ibu 1 & $:$ & pak erlan mau kemana itu? \\
\hline Bpk 3 & $:$ & yak meli aiq juluq \\
\hline Ibu 1 & $:$ & Kenitip meli gorengan \\
\hline Bpk 2 & $:$ & Saya juga nitip jus apel pak \\
\hline Bpk 3 & $:$ & Bisa. Asal sesuai upetinya...hahhaha \\
\hline \multicolumn{3}{|l}{ Kode data: (AK/WKel/Rek 03/58:02/2017) } \\
\hline
\end{tabular}

Klausa 'yaq meli aiq juluq' merupakan wujud pemberitahuan atau informasi yang dilakukan oleh penutur Bpk 3 terhadap lawan tutur Ibu 1. Ujaran dalam bentuk klausa tersebut dilakukan untuk menginformasikan rekan kerjanya agar ia tidak disangka pergiegitu saja saatmengerjakan tugas laporan dosen. Klausa pemberitahuan tersebut merupakan respon terhadap pertanyaan penutur Ibu 1 terhadap penutur Bpk 3.

Sementara itu faktor penyebab Alih kode dalam penelitian ini yaitu faktor lawan tutur, orang ketiga tutur dan topik tuturan. 
1. Faktor Lawan Tutur

Data 1:

\begin{tabular}{|l|l|l|}
\hline Ibu 1 & $:$ & Besok masuk kan? \\
\hline Ibu 2 & $:$ & Ohh...pasti delima...hehe \\
\hline Ibu 2 & $:$ & Daahh... \\
\hline Ibu 1 & $:$ & Tu kan, pasti besok datengnya kesiangan \\
\hline Ibu 1 & $:$ & Oya, Jurnal muamalahnya mana? \\
\hline Bpk 1 & $:$ & Saq ne? \\
\hline Ibu 1 & $:$ & Enggaqn? \\
\hline Bpk 1 & $:$ & Enggaqn araq sekeq \\
\hline Kode data: (AK/WK/Rek 02/14:40/2017) \\
\hline
\end{tabular}

Pada data 1 ditemukan bahwa faktor penyebab alih kode adalah lawan tutur. Hal tersebut bisa dilihat pada awal pembicaraan kedua penutur menggunakan bahasa Indonesia ketika salah seorang dari dua penutur di atas melakukan alih kode bahasa dari bahasa Indonesia ke bahasa Sasak maka lawan tuturnya pun langsung mengikuti alih kode bahasa seperti yang dilakukan oleh penutur pertama.

Data 2.

Bpk 1 : Niniq?

Bpk 2 : Ndeq niniq ne!

Bpk 1 : Brembe tan model nani ne?

Bpk 1 : Kirim ke sini!

Bpk 2 : Oh iya

Kode data: (AK/WK/Rek 02/ 24:37/2017)

Pada data 2 ditemukan bahwa faktor penyebab alih kode adalah lawan tutur. Hal tersebut bisa dilihat pada wal pembicaraan kedua penutur menggunakan bahasa Sasak ketika salah seorang dari dua penutur di atas melakukan alih kode bahasa dari bahasa Sasak ke bahasa Indonesia maka lawan tuturnya pun langsung mengikuti alih kode bahasa seperti yang dilakukan oleh penutur pertama.

Data 3.

\begin{tabular}{|l|l|l|}
\hline Ibu 3 & $:$ & oh araq kabel datam atau ndeq pengecas? \\
\hline Bpk 2 & $:$ & Aneeh, ndeq jauq! \\
\hline Bpk 2 & $:$ & OTG jaq araq ni! \\
\hline Ibu 3 & $:$ & Ape aran OTG? \\
\hline Bpk 2 & $:$ & Flashdisk leq hp tye! \\
\hline Ibu 3 & $:$ & Embe? \\
\hline
\end{tabular}




\begin{tabular}{|l|l|l|}
\hline Bpk 2 & $:$ & Oh ne ne \\
\hline Bpk 2 & $:$ & Kirim file Pdf atau kirim ke Email? \\
\hline Ibu 3 & $:$ & Pdf saja! \\
\hline \multicolumn{2}{|l}{ Kode data: (AK/WK/Rek 02/16:319/2017) } \\
\hline
\end{tabular}

Pada data 3 ditemukan bahwa faktor penyebab alih kode adalah lawan tutur. Hal tersebut bisa dilihat pada wal pembicaraan kedua penutur menggunakan bahasa Sasak ketika salah seorang dari dua penutur di atas melakukan alih kode bahasa dari bahasa Sasak ke bahasa Indonesia maka lawan tuturnya pun langsung mengikuti alih kode bahasa seperti yang dilakukan oleh penutur pertama.

Data 4.

\begin{tabular}{|l|l|l|}
\hline Ibu 3 & $:$ & Naa kan tadi ngajar yang mana yang mana? Yang ini kan! \\
\hline Ibu 2 & $:$ & Atas sedikit \\
\hline Ibu 2 & $:$ & Cobaq cobaq \\
\hline Ibu 3 & $:$ & IKITI oneq no? \\
\hline Ibu 2 & $:$ & Iya bu \\
\hline Ibu 4 & $:$ & SK mengajar genap! kita lihat dulu ini yang di atas \\
\hline Ibu 2 & $:$ & Mengajar muamalah \\
\hline \multicolumn{2}{|l}{ Kode data: (AK/WF/ Rek 02/26:23/2017) } \\
\hline
\end{tabular}

Pada data 4 ditemukan bahwa faktor penyebab alih kode adalah lawan tutur. Hal tersebut bisa dilihat pada awal pembicaraan kedua penutur menggunakan bahasa Indonesia, akan tetapi ketika salah seorang dari dua penutur di atas melakukan alih kode bahasa dari bahasa Indonesia ke bahasa Sasak maka lawan tuturnya pun langsung mengikuti alih kode bahasa seperti yang dilakukan oleh penutur pertama.

2. Hadirnya Penutur Ketiga

Data 1.

\begin{tabular}{|l|l|l|}
\hline Ibu 3 & $:$ & Minuman ini kadaluarsa semua? \\
\hline Bpk 2 & $:$ & Iye unin. \\
\hline Ibu 3 & $:$ & Segerah ne. pacuan \\
\hline Bpk 2 & $:$ & Segerah ke gelutm \\
\hline Ibu 4 & $:$ & Awas mbk El..hati-hati \\
\hline Ibu 3 & $:$ & Beneran ya mbk ini kadalwarsa? \\
\hline Ibu 4 & $:$ & Kayaknya sih mbk \\
\hline Bpk 2 & $:$ & Minum aja kalau Ibu mau \\
\hline Bpk 2 & $:$ & Hahaha... \\
\hline
\end{tabular}


Kode data: (AK/WF/Rek 02/13:00/2017)

Pada data 1 ditemukan bahwa faktor penyebab alih kode adalah hadirnya penutur ketiga. Hal tersebut bisa dilihat pada awal pembicaraan kedua penutur (Ibk 3 dan Bpk 3) menggunakan bahasa Sasak, akan tetapi ketika hadirnya penutur ketiga (Ibu 4) maka secara sepontanitas kedua penutur di awal menggunakan bahasa Indonesia akhirnya melakukan alih kode bahasa menggunakan bahasa penutur ketiga yaitu bahasa Indonesia.

Data 2.

Ibu 3 : Apa sih barangmu itu Erlan ?.ya Allaaah anak ini.

Bpk 3 : Mau wawancara itu ceritanya bu

Ibu 3 : Wawancara apanya?

Bpk 3 : Angkan, engkah pencet-pencet angkaq ni buk

Ibu 3 : Endeqke wah pencet-pencetn

Ibu 2 : Jangan begitu

Ibu 3 : Ya maunya marah terus ne

Kode data: (AK/WKel/Rek 01/10:07/2017)

Pada data 2 ditemukan bahwa faktor penyebab alih kode adalah hadirnya penutur ketiga. Hal tersebut bisa dilihat pada awal pembicaraan kedua penutur (Ibk 3 dan Bpk 3) menggunakan bahasa Sasak, akan tetapi ketika hadirnya penutur ketiga (Ibu 2) maka secara sepontanitas penutur (Ibu 3) di awal menggunakan bahasa Sasak akhirnya melakukan alih kode bahasa menggunakan bahasa penutur ketiga yaitu bahasa Indonesia.

Data 3.

\begin{tabular}{|l|l|l|}
\hline Ibu 1 & $:$ & pak erlan mau kemana itu? \\
\hline Bpk 3 & $:$ & yak meli aiq juluq \\
\hline Ibu 1 & $:$ & Kenitip meli gorengan \\
\hline Bpk 2 & $:$ & Saya juga nitip jus apel pak \\
\hline Bpk 3 & $:$ & Bisa. Asal sesuai upetinya...hahhaha \\
\hline \multicolumn{3}{|c|}{ Kode data: (AK/WKel/Rek 03/58:02/2017) } \\
\hline
\end{tabular}

Pada data 3 ditemukan bahwa faktor penyebab alih kode adalah hadirnya penutur ketiga. Hal tersebut bisa dilihat pada awal pembicaraan kedua penutur (Ibk 1dan Bpk 3) menggunakan bahasa Sasak, akan tetapi ketika hadirnya penutur ketiga (Bpk 2) maka secara sepontanitas penutur (Bpk 3) di awal menggunakan bahasa Sasak akhirnya melakukan alih kode bahasa menggunakan bahasa penutur ketiga yaitu bahasa Indonesia. 


\section{Campur Kode}

Wujud campur kode yang ditemukan dalam penelitian ini berupa kata frasa, klausa dan perulangan kata. Jenis campur kode yang terjadi pada tuturan percakapan sehari-hari dosen di lingkungan Fakultas Syariah dan Ekonomi Islam IAIN Mataram yaitu campur kode ke dalam (Innercode-mixing).Hal ini didasarkan pada data tuturan yang diperoleh peneliti yaitu bahasa Sasak selalu disisipkan pada tuturan komunikasi menggunakan bahasa Indonesia.Penyisipan serpihan bahasa Sasak dalam satu tuturan dengan mitra tutur menunjukkan adanya identifikasi peran atau kepentingan penutur dan mitra tutur dalam komunikasi mereka. Dalam penelitian ini tidak ditemukan serpihan bahasa Indonesia dalam satu kalimat utuh tuturan bahasa Sasak, akn tetapi yang lebih banyak ditemukan adalah kalimat atau tuturan penuh menggunakan bahasa Indonesia tapi selalu diselipi dengan bahasa Sasak.

Sementara itu tujuan campur kode yang ditemukan dalam penelitian ini yaitu: a Adapun tujuan dari campur kode dalam penelitian ini yaitu: penghormatan, penegas, ambigu, heran, spesifik, marah, budaya, informasi, penasaran/ingin tahu, larangan, dan himbauan.

\section{a. Penghormatan}

A: Mana katanya Panitia PKL yang katanya mau lembur itu?

$\mathrm{B}$ : Loo sidekan yang ngomong

(Kode Data: CK/WK/Rek 02/27:02/2017)

kata 'side' dalam bahasa Sasak tergolong bahasa yang selalu diacukan kepada orang yang dari sisi umur lebih tua atau penghormatan kepada orang baru yang dikenal. Penggunaan campur kode dengan menggunakan kata 'side' pada tuturan di atas adalah salah satu bentuk ungkapan rasa hormat kepada lawan tutur.

b. Penegas

A: Presensi ape?

B: Presensi 2 G U SURFIK PS!

B: Udah tame semuanya ini?

(Kode Data: CK/WK/Rek 02/32:15/2017)

penggunaan campurkode kata 'ape' dalam tuturan di atas bertujuan memberikan penegasan terhadap lawan tutur tentang apa yang dicari. Sementara itu penggunaan kata 'tame' juga merupakan pernyataan penegasan atau kepastian dari presensi yang dimaksud oleh lawan tutur.

c. Ambiguitas

A: Yang dari RB tadi ndak dikonfirm?, Kan saya ndak tau!

B: Siapa siswanya? 


\section{C: Anuk pak mukhtamar sama pak Sainun}

Udah...

(Kode Data: CK/WK/Rek 03/44:22/2017)

Penggunaan kata 'anuk' dalam tuturan di atas merupakan bentuk campur kode yang dilakukan oleh penutur C. ambiguitas coba dimunculkan oleh penutur C terhadap lawan tuturnya. Kata 'anuk' sendiri memiliki banyak makna salah satunya menunjuk, atau lupa dengan nama sesuatu. Sehingga kata 'anuk' condong kemudian menimbulkan ambiguitas itu sendiri.

d. Ingin tahu/penasaran

A: My Blink lengkap dulu, masukan ke leptop

B: embe laptop side?

(Kode Data: CK/WK/Rek 04/16:09/2017)

Penggunaan kata 'embe' dalam tuturan di atas merupakan bentuk campur kode yang dilakukan oleh penutur B. adapun tujuan dari penggunaan kata 'embe' sendiri lebih pada rasa ingin tau atau ingin memastikan keberadaan leptop mitra tutur (A).

A: Nak,side pisukenya berapa?

B: Saya?

A: $\mathrm{Hmm}$

B: Kan sudah saya ceritakan tadi,Tiga juta?

(Kode Data: CK/WF/Rek 04/11:06/2017)

Penggunaan frasa 'side pisuke-nya' dalam tuturan di atas merupakan bentuk campur kode yang dilakukan oleh penutur A. adapun tujuan dari penggunaan frasa 'side pisuke-nya' sendiri lebih pada rasa ingin tau atau ingin memastikan keberadaan berapa pisuke yang diterima oleh mitra tutur (B).

e. Heran

A: Absen fikih muamalah

B: Astage jangan ngomong kayak begitu bang, aku membutuhkan dia

(Kode Data: CK/WK/Rek 03/14:42/2017)

Penggunaan kata 'astage' dalam tuturan di atas merupakan bentuk campur kode yang dilakukan oleh penutur B. adapun tujuan dari penggunaan kata 'astage' sendiri lebih pada ungkapan rasa heran atau kaget yang dimunculkan oleh penutur $B$ terhadap lawan tuturnya yaitu penutur A.

A: Waduh

B:Anehmati internetn!

C: Share it dah 
(Kode Data: CK/WK/Rek 02/50:32/2017)

Penggunaan kata 'aneh' dalam tuturan di atas merupakan bentuk campur kode yang dilakukan oleh penutur B. adapun tujuan dari penggunaan kata 'astage' sendiri lebih pada ungkapan rasa heran atau kaget yang dimunculkan oleh penutur B terhadap lawan tuturnya yaitu penutur A.

f. Spesifik
A: Ya Allah
B: Jeruk sebiji, lagi lime jeruk itu cobak, kecil lagi

(Kode Data: CK/WK/Rek 03/58:33/2017)

Penggunaan kata 'aneh' dalam tuturan di atas merupakan bentuk campur kode yang dilakukan oleh penutur B. adapun tujuan dari penggunaan kata 'sebiji' sendiri lebih pada ungkapan menyebut sesuatu secara spesifik.

g. Marah
A: Yato satu mana?
B: Lombok Tengah tapisanaaaaaaaa.........
A: Lasingan rumah sakit di sana kenapa di Mataram?
B: Jaga -jaga kalo terjadi apa-apa gitu loh!

(Kode Data: CK/WK/Rek 05/35:12/2017)

Penggunaan kata 'lasingan' dalam tuturan di atas merupakan bentuk campur kode yang dilakukan oleh penutur A. adapun tujuan dari penggunaan kata 'lasingan' sendiri sebagai ungkapan rasa kesal dan marah dengan bahasa yang sopan. Kata 'lasingan' akan memiliki kekuatan makna marah itu sndiri ketika kata lasingan dibarengi dengan intonasi suara tinggi. Pada konteks di atas penutur A cukup marah dengan penutur B disebabkan ketidaktahuan dari penutur B tentang lokasi rumah sakit Mataram.

h. Budaya

A: Saya datang limabelas orang

B: Resepsi itu saya kalo mau datang ya datang, nggak iya nggak

A: Ndak acara begawe gitu?

(Kode Data: CK/WK/Rek 05/40:52/2017)

Penggunaan kata 'begawe' dalam tuturan di atas merupakan bentuk campur kode yang dilakukan oleh penutur A. adapun tujuan dari penggunaan kata 'begawe' sendiri sebagai ungkapan simbolisasi daerah. Sebab, terminology kata 'begawe' sendiri hanya digunakan di suku Sasak.Sehingga terma tersebut kemudian menjadi seseuatu yang egitu disukai oleh banyak orang. 
A: Tadi yg nanya kapan nikah dari pihak mana?

B: Dari pihak laki-laki dan ya ke pihak perempuan

A: Jadi maskawinnya ditanyakan kepada pihak walinya?

(Kode Data: CK/WK/Rek 06/21:04/2017)

Penggunaan kata 'maskawin' dalam tuturan di atas merupakan bentuk campur kode yang dilakukan oleh penutur A. adapun tujuan dari penggunaan kata 'begawe' sendiri sebagai ungkapan simbolisasi daerah. Sebab, terminology kata 'maskawin' sendiri hanya digunakan di suku Sasak.Sehingga terma tersebut kemudian menjadi sesuatu yang egitu disukai oleh banyak orang.Penyisipan terma budaya oleh penutur memang memiliki tujuan tersendiri disamping tujuan yang lebih besar yaitu promosi budaya.
A: Kok lama sekali
B: Belum pisuke itu
A: Masak belum?

(Kode Data: CK/WK/Rek 06/26:59/2017)

Penggunaan kata 'pisuke' dalam tuturan di atas merupakan bentuk campur kode yang dilakukan oleh penutur B adapun tujuan dari penggunaan kata 'pisuke' sendiri sebagai ungkapan simbolisasi daerah. Sebab, terminology kata 'pisuke' sendiri hanya digunakan di suku Sasak.Sehingga terma tersebut kemudian menjadi ikonitas orang. Lombok Penyisipan terma budaya oleh penutur memang memiliki tujuan tersendiri disamping tujuan yang lebih besar yaitu promosi budaya.

i. Informasi

A: Pisuke itu untuk roahnya saja bukan untuk apa namanya biaya hidup kayak

B: Ndak, roah begawe nyogkolannya itu ada yg minta sekian-sekian tergantung nego lagi disana kalau sudah ada

(Kode Data: CK/WKel/Rek 09/40:51/2017)

Penggunaan klausa 'roah begawe nyongkolan' dalam tuturan di atas merupakan bentuk campur kode yang dilakukan oleh penutur B. adapun tujuan dari penggunaan klausa 'roah begawe nyongkolan' tersebut sebagai ungkapan simbolisasi terma kedaerahan yang kuat yang tersemat dalam diri dan lingkungan penutur.

A: kenapa internetnya?

B: Nah ndek taok tiang saq tie jaq!

A: Ndak nyambung?

B: Kalo nyambung kan flashdisk-nya nyala dia

(Kode Data: CK/WKel/Rek 04/43:31/2017) 
Penggunaan klausa 'endeq taoq tiang saq tie jaq' dalam tuturan di atas merupakan bentuk campur kode yang dilakukan oleh penutur B. adapun tujuan dari penggunaan klausa 'endeq taoq tiang saq tie jaq' tersebut sebagai ungkapan ketidaktahuan penutur Btentang jaringan internet.Ujaran tersebut diujarkan karena penutur B benar-benartidak tahu kenapa Internetnya mati dan dia tidak tau apapun tentang Internet.

j. Larangan

A: Apa sih barangmu itu Erlan ???ya Allaaah anak ini....

B: Mau wawancara itu ceritanya

C: Engkah pencet-pencetangkak ni buk cobak buk di pencet-pencetcobakbuk A: Jangan begitu ....

(Kode Data: CK/WKel/Rek 01/10:07/2017)

Penggunaan klausa 'engkah pencet-pencet angkaq tie buk' dalam tuturan di atas merupakan bentuk campur kode yang dilakukan oleh penutur C. adapun tujuan dari penggunaan klausa 'engkah pencet-pencet angkaq tie buk' tersebut sebagai ungkapan larangan agar dilakukan oleh penutur A.

k. Himbauan

A: Sapa punyak ini?

B: Eee ini anuk saya belum di minum saya

A: apekan ones onek pak Jihad!

(Kode Data: CK/WKel/Rek 10/36:15/2017)

Penggunaan klausa 'apekan ones onek' dalam tuturan di atas merupakan bentuk campur kode yang dilakukan oleh penutur A. adapun tujuan dari penggunaan klausa 'apekan ones onek' tersebut sebagai ungkapan himbauan agar mitra tutur B lebih berhati-hati menggunakan gelas minuman orang.

Adapun faktor penyebab terjadinya campur kode dalam tuturan ini yaitu; faktor keinginan untuk menjelaskan, identifikasi ragam dan identifikasi peranan.

\section{E. Simpulan}

Berangkat dari hasil pembahasan yang diteliti persoalan alih kode dan campur kode dalam percakapan keseharian di Fakultas Syariah dan Ekonomi Islam IAIN Mataram disimpulkan bahwa wujud alih kode dan campur kode yang ditemukan yaitu berwujud kata, frasa dan klausa. Jenis alih kode yang ditemukan adalah alih kode internal (inner code-switch) dan jenis campur kode yang ditemukan berupa campur kode ke dalam (inner mixing-code). Sedangkan tujuan alih kode yang ditemukan 
berupa: penegasan, melemahkan, kepastian, penasaran, penjelsan, menyindir, saran, tawaran dan pemberitahuan. Adapun tujuan campur kode yang ditemukan berupa: penghormatan, penegasan, ambiguitas, keheranan, spesifik, marah, budaya, informasi, penasaran, larangan dan himbauan. Faktor penyebab alih kode berupa: lawan tutur dan hadirnya penutur ketiga. Sedangkan faktor penyebab campur kode berupa: faktor keinginan untuk menjelaskan, faktor identifikasi ragam dan faktor identifikasi peranan

\section{Daftar Pustaka}

Aslinda, dan Shafyahya, Leni. 2007. Pengantar Sosiolinguistik. Bandung: Reflika Aditama.

Chaer, Abdul. 1994.Linguistik Umum. Jakarta: Rineka Cipta.

Chaer, Abdul dan Agustina.Leonie.2004.Sosiolinguistik: Perkenalan Awal. Jakarta: Rineka Cipta.

Dandan, Wang. 2008.Pemilihan Pemakaian Bahasa Warga Tionghoa di Kotamadya Yogyakarta: Suatu Kajian Sosiolinguistik. Yogyakarta: Program Pascasarjana Universitas Negeri Yogyakarta.

Fasold, R. 1987.The Sociolinguistics of Society. Oxford: Blackwell Publishers Ltd.

Kridalaksana, Harimurti. 2010.Kamus Linguistik. Jakarta: Gramedia Pustaka Utama.

Kusumastuti, Dyah. 2010.Peristiwa Campur Kode Bahasa Jawa dan Bahasa Indonesia di Daerah Sukoharjo.Tidak diterbitkan.

Nababan, P. W. J. 1986.Sosiolinguistik Suatu Pengantar: Jakarta: Gramedia Pustaka Utama.

Ohoiwutun, Paul. 1997. Sosiolinguistik: Memahami Bahasa dalam Konteks Masyarakat dan Kebudayaan. Terjemahan oleh Herman Sudrajat. Jakarta: Kesaint Blanc.

Refnita, Lely. 2009.Improving Students' Awareness and Achievement on Englsh Grammar Through The Effective Use of Code-Switching (Proceeding of The First COTEFL International Conference). Purwokerto: Universitas Muhammadiyah Purwokerto.

Ridan Umi Darojah diunduh dari laman http://ridanumidarojah.blogspot. co.id/2013/05/pengertian-alih-kode-dan-campur-kode.html

Sudaryanto.1988.Metode Linguistik. Yogyakarta: Gajah Mada University Press.

Suwito.1982.Sosiolinguistik: Pengantar Awal. Surakarta: Henanry Offset.

Subyakto, S. U. 1998.Psikolinguistik Suatu Pengantar. Jakarta: Depdikbud. 
El-Tsaqafah: Jurnal Jurusan PBA, Vol. 18, No.1, 2019

Wardhaugh, R. 1986.An Introduction to Sociolinguistics. New York: Basil Blackwell.

Komunitas Anak Sastra diunduh dari http://anaksastra.blogspot.co.id/2009/02/ alih-kode-dan-campur-kode.html

Wikipedia diunduh dari laman https://id.wikipedia.org/wiki/Diglosia

Akmaluddin. 2018. Jurnal Mabasan Vol. 12 No. 1 Tahun 2018 "Realitas Penggunaan bahasa Indonesia Ragam Tulisan pada Lembaga Pemerintahan”. Mataram: Kantor Bahasa Provinsi NTB. . 2016. Jurnal Mabasan Vol. 10 No. 2 Tahun 2016 "Problematika Bahasa Indonesia Kekinian: Sebuah Analisis KesalahanBerbahasaIndonesia Ragam Tulisan”. Mataram: Kantor Bahasa Provinsi NTB. 